\title{
A Inclusão da Pessoa com Autismo no Ensino Superior
}

\begin{abstract}
Resumo: A educação superior para pessoas com transtorno do espectro do autismo (TEA) é um campo que vem se expandindo, porém com poucos dados publicados no Brasil sobre a experiência desse tipo de inclusão na universidade. Assim, este estudo busca conhecer as ações tomadas pela Universidade Federal da Bahia (UFBA), através da Pró-Reitoria de Ações Afirmativas e Assistência Estudantil (PROAE), para melhorar a inclusão de pessoas com TEA, identificando quais as medidas práticas que foram pensadas e viabilizadas para esses alunos e como elas são implementadas na prática dos estudantes com autismo. A gravidade do transtorno varia em função da intensidade do comprometimento dos sintomas, que pode variar desde pessoas que têm déficits mais sutis, como dificuldade de expressar sentimentos e de compreender metáforas, até pessoas que não conseguem se comunicar verbalmente e nem por gestos. Portanto, foi feito um estudo qualitativo exploratório, com pesquisa documental e entrevistas semiestruturadas, acrescido de investigação documental no site do Núcleo de Apoio à Inclusão do Aluno com Necessidades Educacionais Especiais (NAPE), da UFBA. Por fim, foram feitas entrevistas semiestruturadas com dois estudantes da UFBA com diagnóstico de autismo, uma mãe de um dos estudantes e uma funcionária do NAPE. Trata-se de um estudo exploratório, que sugere uma possível invisibilidade de pessoas com autismo na universidade, apesar de existirem programas e legislações que facilitem a inclusão desses alunos no meio acadêmico.
\end{abstract}

Palavras-chave: Inclusão. Autismo. Universidade.

\section{Introdução}

Do ponto de vista biomédico o Transtorno do Espectro do Autismo (TEA) se constitui em um grupo heterogêneo de transtorno do neurodesenvolvimento, que envolve déficits persistentes na comunicação e interação social em vários contextos, associado a padrões restritos e repetitivos de interesses. (AMERICAN PSYCHIATRIC ASSOCIATION, 2014) A gravidade do transtorno varia em função da intensidade do comprometimento dos sintomas, que pode variar desde pessoas que têm déficits mais sutis como dificuldade de expressar sentimentos e de compreender metáforas, até pessoas que não conseguem se comunicar verbalmente e nem por gestos. No campo da interação, vai desde pessoas que interagem de forma unilateral, sem ter empatia ou percepção dos sentimentos alheios, até pessoas que não aceitam a interação e preferem se isolar. Com relação aos interesses restritos, podem variar de interesses intensos por assuntos incomuns, como esoterismo,
Wellington Farias dos Santos Universidade Federal da Bahia (UFBA)

wellingtonf278@gmail.com Vinicius Santos Santana Universidade Federal da Bahia (UFBA)

igvinisantos@gmail.com Lucas de Souza Santos Dias Universidade Federal da Bahia (UFBA)

Issdias2000@gmail.com

Cristina Maria D’Ávila Teixeira

Universidade Federal da Bahia (UFBA)

cristdavila@gmail.com Milena Pereira Pondé

Universidade Federal da Bahia (UFBA)

milenaponde@bahiana.edu.br 
dinossauros, física quântica até interesses restritos e repetitivos de cunho sensorial, como rodar objetos, manipular saliva e automutilação. O foco de interesses, portanto, pode gerar comportamentos adaptativos ou desadaptativos, este último, sobretudo quando predominam as alterações sensoriais. Estudos antropológicos apontam que esse conjunto de sinais e sintomas definidos pela biomedicina como TEA, pode não fazer sentido fora do âmbito da medicina. Há autores que argumentam que o discurso biomédico dominante se foca muito nos sintomas, esquecendo de saber sobre a descrição da experiência das pessoas que vivem com o autismo. (SOLOMON; BAGATELL, 2010) Segundo os ativistas autistas o foco nas questões relacionadas ao autismo deve ser a identificação de estratégias para lidar com os sintomas que o próprio autista considera problemático, bem como poder investir nas suas percepções e habilidades que são únicas. (BAGATELL, 2010)

A inclusão no processo educacional da pessoa com autismo no Brasil é um tema que vem sendo mais amplamente difundido a partir do início do século XXI e faz parte dos programas de educação para pessoas com deficiência e com necessidades especiais.

A Educação Especial no Brasil pode ser compreendida em três momentos históricos que embora distintos ainda ocorrem em diferentes espaços por falta de entendimento dos Paradigmas de Ação da Educação Especial.

O paradigma inicial, denominado Paradigma de Ações, adotado no final do século XIX, conforme cita Aranha (2001, p. 161) "caracterizou-se pela retirada das pessoas de suas comunidades de origem e por sua manutenção em instituições residenciais segregadas (instituições totais) e escola especiais, locais esses distantes de suas famílias". Esse paradigma de ação caracterizou-se pela institucionalização das pessoas com deficiência em instituições fechadas. Em meados do século XX surge o paradigma de serviços:

[...] iniciado nos Estados Unidos em meados do século XX, passou a se caracterizar pela oferta de serviços. Entidades financiadas pelo poder público passaram a oferecer um amplo leque de modalidades de serviços, na sua maior parte em ambiente segregado, mantendo-os disponíveis até que a pessoa com deficiência fosse considerada "pronta" para sua integração na comunidade. (ARANHA, 2001, p. 162) 
O paradigma da oferta de serviços argumenta Aranha (2001, p. 162),

[...] representou um grande avanço quando comparado com o da institucionalização total. Entretanto, ainda se mostrou limitado e equivocado, ao supor que alguém possa realmente se "habilitar" para a integração social, através de uma vivência segregadora, em ambiente não representativo da vida na sociedade mais ampla, e em convivência quase que exclusivamente com outras pessoas com deficiência.

Determinada pelos resultados da investigação científica, pelas ideias defendidas por membros da academia científica e pela pressão de grupos organizados da sociedade, nova mudança começa a ocorrer na prática das relações com a população de pessoas com deficiências.

O Paradigma de Suportes constitui-se da disponibilização, ao cidadão com deficiência, todo e qualquer apoio que se mostre necessário para a otimização de seu potencial para uma vida de qualidade e que permita sua real inclusão em todas as áreas de sua existência: vida doméstica, escolar, familiar, social mais ampla, profissional e econômica.

No paradigma de suportes passa a ser usado o termo inclusão, termo este que apresenta um caráter mais abrangente, visualizando a deficiência numa perspectiva social.

Avançando ainda mais no movimento de garantir respeito aos direitos de igualdade às pessoas com deficiência, Aranha (2001, p. 164) destaca que:

[...] encontra-se em processo de efetivação, no momento, em países mais desenvolvidos, um quarto paradigma, denominado Paradigma do Empowerment. Evitando o risco de uma tradução não representativa do real significado semântico desse termo, dado não se contar com vocábulo correspondente na língua coloquial portuguesa, [...] Empowerment significa 'garantir o poder', 'assegurar o poder' a alguém. Na área em que está aqui sendo utilizado, significa garantir à pessoa com deficiência o poder decisório e o de determinação no encaminhamento de sua própria vida; significa empossar de fato as pessoas com deficiência da possibilidade de exercer seu direito de assumir maior controle possível sobre a qualidade de suas vidas. Neste paradigma, o controle da aquisição de suportes encontra-se 
com os indivíduos com deficiência e/ou seus advogados, se necessário. Na prática, ele se traduz na concessão, pelo governo público, aos cidadãos com deficiência, de verba que eles possam utilizar na compra direta de serviços que desejam e/ ou necessitam. Com isso, pretende-se tanto promover a maior autonomia da pessoa com deficiência no trato de sua própria existência, como estimular uma suposta melhor qualificação dos serviços disponíveis. Este paradigma, mais recente na caminhada histórica da atenção à pessoa com deficiência, encontra-se, entretanto, em início de implementação em alguns países considerados mais desenvolvidos.

Assim, no primeiro paradigma o aluno com deficiência e com necessidades especiais era excluído de qualquer tipo de escolarização. O segundo momento ainda caracterizou pela segregação em um contexto escolar regular, pois as instituições com objetivos educacionais pedagógicos funcionavam num sistema paralelo ao da educação geral, que são as escolas especiais como Associação de Amigos dos Autistas (AMA) e Associação de Pais e Amigos dos Excepcionais (APAE); e o último vigente no Brasil, quando a escolarização do público-alvo da educação especial passou a ocorrer no mesmo sistema de ensino dos demais alunos, ou seja, nas escolas regulares. (MENDES, 2003) Em termos ideais, considera-se que a inclusão pedagógica dos alunos com deficiência e particularmente do autista deve se dar, preferencialmente, nas escolas regulares, uma vez que se entende que as pessoas com deficiência e necessidades especiais devem estar inseridas na sociedade de uma forma plena.

As mudanças ocorridas nas práticas da educação especial foram alavancadas por mudanças na legislação, que por sua vez foram movidas por movimentos sociais. No caso do autismo foram em grande parte capitaneados pelos pais dos indivíduos com esse transtorno, que foram forçando a sua viabilização, sobretudo ao longo dos últimos 20 anos. Em 1998, o Ministério da Educação (MEC) formalizou em um documento oficial as adaptações curriculares que deveriam ser feitas nos Parâmetros Curriculares Nacionais (PCN). (BRASIL, 1998) Esse documento inicial foi seguido em 2001 pelas Diretrizes Nacionais para a Educação Especial na Educação Básica. (BRASIL, 2001) O documento assinala que os sistemas de ensino deverão assegurar aos educandos com autismo currículos, métodos, técnicas, recursos educativos e organização específicos para atender às suas necessidades; bem como professores com 
especialização adequada em nível médio ou superior. Em dezembro de 2012, a Lei $n^{\circ}$ 12764/2012 (BRASIL, 2012) definiu a obrigatoriedade de vagas em escolas públicas e privadas para o aluno com TEA, bem como o direito a acompanhante especializado, quando necessário. Após a promulgação dessa lei, as instituições de ensino públicas e privadas têm buscado preparar-se e adequar-se para receberem esses alunos.

As últimas duas décadas têm assistido um crescente movimento no mundo para incluir no seio da sociedade pessoas que estiveram invisíveis. Pessoas com Síndrome de Down, com deficiências visuais, surdez e deficiências físicas têm progressivamente ocupado espaços sociais e protagonizado importantes mudanças nas formas de pensar e agir em relação à diferença. O autismo, que enquanto condição médica tem 75 anos de idade, apenas recentemente passou a ser pensado como uma condição que requer atenção especial para inclusão pedagógica. A produção científica brasileira sobre a escolarização de crianças diagnosticadas com TEA em classes comuns de escolas regulares concentra-se nas universidades públicas do Sudeste, sendo realizadas predominantemente por pessoas com formação inicial na área da Saúde, que realizaram estudos em nível de pós-graduação em Educação, em linhas de pesquisa em Educação Especial. A Educação Especial parece se manter numa perspectiva de reabilitação em Saúde, fazendo com que o professor suponha que precise se submeter a um saber biomédico para poder ensinar o seu aluno. Dessa forma, aquilo que se entende como escolarização de crianças diagnosticadas com TEA continua muito próximo da clínica da normalização. (RODRIGUES; ANGELUCCI, 2018)

Diante dos desafios expostos, as instituições de ensino superior têm tentado preparar-se para receber estudantes com TEA. Na Universidade Federal da Bahia (UFBA) o Núcleo de Apoio à inclusão do aluno com necessidades educacionais especiais (NAPE) foi criado através da Portaria nº 74, de 26 março de 2008 (UNIVERSIDADE FEDERAL DA BAHIA, 2008) e vinculado à PróReitoria de Ações Afirmativas e Assistência Estudantil (PROAE), com o objetivo de contribuir para reduzir as barreiras enfrentadas por pessoas com deficiência. Diante da necessidade de integrar as leis à sua aplicação prática, este estudo busca conhecer as atitudes tomadas pela UFBA, através da PROAE, para melhorar a inclusão de pessoas com TEA, identificando quais as medidas práticas que foram pensadas e viabilizadas para esses alunos. Por outro lado, 
buscamos conhecer em que medida a comunidade acadêmica percebe os efeitos dessas ações.

\section{Método}

Este trabalho é um estudo qualitativo exploratório, com pesquisa documental e entrevistas semiestruturadas. A pesquisa documental foi realizada no site do NAPE, da UFBA, buscando identificar quais os programas e serviços disponíveis para facilitar a inclusão de alunos com autismo, bem como a visibilidade dos serviços e acessibilidade aos possíveis usuários. Para conhecer a realidade da inclusão, foram feitas entrevistas semiestruturadas com estudantes da UFBA que têm diagnóstico de autismo e que aceitaram participar do estudo de forma anônima, a mãe de um dos usuários e com um funcionário da UFBA envolvido em programas para pessoas com autismo. Foram elaborados guias de entrevistas semiestruturadas para auxiliar a coleta das informações.

Todas as entrevistas foram realizadas via aplicativo de rede social, tendo sido gravadas e transcritas. Os entrevistados concordaram que os dados da pesquisa fossem publicados, garantindo-se o anonimato em relação aos informantes.

Após a transcrição, as respostas das entrevistas foram codificadas em categorias, assim como as informações obtidas no site. (GIBBS, 2009) As categorias levantadas nas diferentes fontes foram comparadas, buscando identificar pontos de contraste e de identidade nas diferentes fontes. (PONDÉ; MENDONÇA; CAROSO, 2009)

\section{Resultados}

Foram entrevistados dois estudantes da UFBA que têm o diagnóstico de autismo, a mãe de um dos estudantes e uma funcionária. O site do NAPE foi consultado, buscando informações relativas à inclusão de pessoas com autismo. Foram levantadas categorias das entrevistas e da busca realizada no site do NAPE em maio de 2019, que serão apresentados a seguir.

\section{Site Institucional}

O NAPE é um órgão vinculado à PROAE, da UFBA . Foi criado através da Portaria $n^{\circ}$ 74, de 26 março de 2008 (UNIVERSIDADE FEDERAL DA BAHIA, 2008), tendo o objetivo de contribuir para 
a inclusão da pessoa com deficiência na UFBA. A meta do NAPE é eliminar barreiras atitudinais, arquitetônicas, comunicacionais, tecnológicas, didáticas e culturais, que impossibilitem a inclusão. O vídeo institucional no site do NAPE, disponível para acesso público, faz referência a três necessidades especiais; ${ }^{1}$ deficiência visual, deficiência física e auditiva, trazendo entrevistas de estudantes com essas necessidades. O órgão assiste aos estudantes com as deficiências citadas, garantindo acesso a material didático especializado e auxílio aos professores; oferece suporte pedagógico com tecnologia assistiva, com apoio ao estudante nas suas necessidades. No vídeo constam depoimentos de aluno com deficiência visual e com física, bem como informativos sobre demandas de acessibilidade física e adaptação dos textos para deficiência visual. Consta no site do NAPE edital para seleção de bolsistas de 2018 em programa de monitoria de mobilidade e programa de apoio pedagógico para o aluno com deficiência. A descrição das atribuições informa que os monitores selecionados deverão auxiliar na locomoção de alunos com deficiência física e na adaptação de material pedagógico, especificamente digitalização de livros e textos acadêmicos para pessoas com deficiência auditiva.

Não existe nenhuma menção explícita no site do NAPE a programas ou políticas direcionadas a pessoas com problemas mentais e nem a pessoas com TEA, não havendo nenhum programa para autismo.

\section{Entrevista com Estudantes com diagnóstico de autismo}

Nenhum dos dois estudantes entrevistados fez prova pelo sistema de inclusão, ao fazerem o Exame Nacional do Ensino Médio (ENEM), não solicitaram fazer uma prova diferente e nem anunciaram a condição de TEA.

Dos dois estudantes com autismo entrevistados um não conhecia o NAPE e o outro usou apenas uma vez, quando teve dificuldades específicas em uma disciplina, com um professor. Entre as dificuldades e demandas, os alunos citaram dificuldades de interação com os colegas e um deles disse ter dificuldades no estágio. A dificuldade de interação leva a dificuldade de realizar trabalhos em grupo, pois não conseguem se inserir nas equipes. Um dos estudantes se queixou que as pessoas o consideravam "estranho", ${ }^{2}$ tendo sido inclusive dispensado do estágio com essa justificativa. Ele não gosta de se identificar como pessoa com autismo, acha que as suas conquistas
(1) NAPE - Vídeo Institucional: https://youtu.be/fM7ik_IWXPE (2) Grifo do entrevistado. 
(3) Grifo do entrevistado. (4) Grifo do entrevistado. seriam diminuídas caso o fizesse. Apesar disso, compreende que foi dispensado do estágio apenas por ser uma pessoa "estranha", ${ }^{3}$ pois desempenhava bem as suas funções e a pessoa que o demitiu the deu a entender que o motivo principal da demissão é que ela "não ia com a cara dele". ${ }^{4} \mathrm{O}$ outro estudante referiu queixas mais gerais, concernentes à estrutura da universidade, mas faz questão de frisar que não é nada específico relacionado ao autismo: "Gostaria que a estrutura da universidade fosse melhor, com menos bagunça, pois os horários são ruins, tem muita sujeira, as instalações em geral são ruins e não tem cantina", no entanto ele sentiu dificuldade de ficar no meio dos outros alunos. Nenhum dos dois achou que precisasse de adaptação no conteúdo pedagógico.

Dentre as fontes de ajuda está a família, ajuda no que é possível, especificamente a mãe; para ambos os entrevistados. Em relação a como poderiam ser ajudados, um deles mencionou que ajudaria se os colegas tivessem mais tolerância consigo. O outro pareceu menosprezar o seu próprio curso, esquivando-se da necessidade de ajuda: "Eu sendo autista não tem nada que possa melhorar, mas eu lido com arte não com cirurgia do cérebro". Ressalta-se que a mãe revelou que esse aluno foi reprovado em uma disciplina por dificuldades com a avaliação, mas mesmo assim ele não se queixou.

\section{Entrevista com mãe de estudante portador de TEA}

A mãe relata que o seu filho foi reprovado, o filho se matriculou em uma matéria que já havia perdido e o motorista da mãe disse à professora que ele era autista, então a professora passou a olhá-lo de outra maneira, entendendo as dificuldades e se preocupou em fazer a prova individualizada para o aluno. Essa professora procurou a mãe e indicou o NAPE, sendo a primeira ocasião que ela soube da existência do órgão. A professora confessou que não sabia a prova que faria para o aluno, mas que observava que ele sabia a matéria, então estabeleceu a nota a partir desse critério. A mãe acha que o diretor da faculdade não sabe sobre o NAPE, pois nunca o indicou.

A mãe relata que uma das dificuldades enfrentadas estava relacionada a uma matéria que envolvia muitos cálculos, de modo que o seu filho foi reprovado. Ele precisava de auxílio, mas a mãe não sabia como fazer. A mãe pediu à psiquiatra para falar com o diretor da faculdade, mas não houve sucesso no encontro. As pessoas da faculdade sabem que seu filho é autista, pois tem 
comportamentos diferentes, como lamber material sujo de argila, durante aulas de escultura, mas não há intervenções direcionadas para facilitar a sua inclusão, de modo que ele fica sempre isolado. A mãe nunca soube se alguém fez piadas, pois ele sempre fica quieto. Aparentemente ele não se incomoda, mas também não se integra. A mãe sugere que deveria haver um trabalho de inclusão dentro da universidade, para que as pessoas chamassem seu filho, para que ele sentisse que existe ali, não apenas permanecer quieto no canto. "A universidade precisa saber que existem outras necessidades além de não saber andar e enxergar. No Serviço Médico Universitário (SMURB) também deveria ter algo nesse sentido, só tem psicanálise. O SMURB deveria ter o cuidado de indicar que o aluno tem alguma deficiência/dificuldade".

Além disso, a mãe relata que o pai sempre negou apoio ao filho com autismo. O diagnóstico foi com 12 anos, a mãe ajuda no que pode. Na matrícula do ENEM não havia um local para informar sobre as necessidades do filho. "Tinha até amamentação, mas não tinha nada para autismo. Não existe autismo incluído nas deficiências na inscrição do vestibular, menciona-se apenas a surdez, a deficiência física e visual. Não havia sequer opção para outros. Na prova de habilidades específicas fez a mesma prova, mas sozinho em outra sala". Depois que soube do NAPE, a cada início de semestre o NAPE disse que falaria com os professores. A mãe manda uma foto com os horários do filho, para o NAPE auxiliar. Um professor disse que só aceitaria ele em aula com um acompanhante, pois ele usaria material químico. Exigiu que fosse funcionário da UFBA, "pois de fora ia querer diploma, dizia o professor." Outro professor pediu acompanhamento quando fizeram trabalho na rua, pois ele tinha receio que ele comesse materiais químicos e que fosse atropelado na rua. Não sabe se o NAPE de fato faz alguma mediação com os professores, mas a mãe vem fazendo isso pessoalmente com os professores a cada início de semestre. "Os professores me olham estranho. Eu não sei se o NAPE de fato fala com os professores, mas eu falo."

\section{Funcionário do NAPE}

Segundo o funcionário do NAPE, o órgão existe desde 26 de março de 2008, vinculado a PROAE para atender estudantes com necessidades especiais. Dentre as dificuldades e demandas dos alunos as razões elencadas para buscar o órgão são: dificuldade 
com a sala de aula muito cheia, o aluno se sente desconfortável nas avaliações (provas e trabalhos) e o professor tem dificuldade com o aluno.

O Núcleo oferece como fontes de ajuda reuniões com o professor para saber quais são as dificuldades e depois com o aluno e a família. A equipe do núcleo de apoio é constituída por uma psicóloga e uma pedagoga, que tentam identificar a disciplina de dificuldade para o aluno e realizam uma reunião. Cada aluno tem as suas especificidades, por exemplo alguns são mais inibidos, alguns preferem pegar menos matérias no semestre, outros têm dificuldades de adaptação à carga semestral de disciplinas que foi matriculado. É a partir das dificuldades específicas que o Núcleo começa a atuar. Fazem uma reunião de avaliação das necessidades.

\section{Discussão}

Esse é um estudo qualitativo, exploratório, com uma amostra pequena, que busca fontes distintas na tentativa de sugerir informações sobre a inclusão da pessoa com autismo na universidade. Até onde pesquisamos, são poucos estudos que discutem a inclusão da pessoa com autismo nas universidades no Brasil. O aspecto que foi recorrente nas fontes de informações consultadas é que ainda não existem programas estruturados para intervenção com os alunos com TEA na UFBA.

As entrevistas com as pessoas com autismo revelaram poucas necessidades, como melhor aceitação pelo grupo de colegas e nos estágios, dificuldade específicas em algumas disciplinas e queixas gerais relativas a problemas comuns a todos na universidade. Ficou patente nas narrativas dos alunos a escolha por permanecer invisível, por não quererem ser identificados como indivíduos com autismo, ou mesmo por preferirem evitar ao máximo o contato interpessoal. Os alunos não fazem queixas específicas e não se colocam espontaneamente na busca de auxílio para o seu processo inclusivo, seja por desconhecerem quais órgãos devem procurar, seja por não quererem se expor, ou mesmo por falta de iniciativa. As entrevistas revelam que os alunos não conhecem os órgãos aos quais devem se dirigir para solicitar auxílio no que se refere à inclusão na universidade. Por outro lado, essas pessoas são invisíveis aos órgãos, pois a sua condição de deficiência não é nomeada no local da matrícula, havendo indicação apenas para as 
deficiências relacionadas à locomoção, surdez e cegueira. O site do órgão responsável pela inclusão, o NAPE, indica dispositivos claros de inclusão voltados para essas mesmas deficiências: o programa de bolsista para auxiliar na locomoção e digitalização de livros, assim como facilidades que auxiliam a inclusão dos alunos com deficiências visuais e/ou auditivas. O autismo, no entanto, não é citado como deficiência no referido site, tornando essa condição invisível para quem procura informação através do site do órgão responsável pela inclusão de alunos com deficiência.

Um aluno revelou reprovação em disciplina, aspecto que foi revertido tão logo a professora teve acesso à informação de que ele era autista. Mesmo sem saber exatamente como programar atividades específicas para o aluno, a professora foi capaz de mudar a sua percepção sobre ele e buscar uma forma de avaliá-lo, permitindo que avançasse no seu percurso acadêmico. Levanta-se aqui a questão se existe índice de reprovação ou evasão aumentado para pessoas com autismo que não informam sobre a sua deficiência e nem mesmo são orientadas a fornecer essa informação. As entrevistas trazem também a queixa dos professores sobre o despreparo em relação a como realizar uma inclusão pedagógica adequada. Pode ser que os professores também se questionem sobre a inclusão social desses alunos. Como não entrevistamos professores, não podemos avançar nessa discussão; mas é possível que o treinamento dos professores em relação às necessidades específicas da população de pessoas com TEA, possa ajudá-los a receber melhor esses alunos e auxiliar na sua inclusão pedagógica e social, evitando o sentimento de exclusão e inadequação que é relatado por um dos alunos entrevistados e pela mãe do outro aluno.

As respostas dos alunos foram curtas e, algumas vezes, evasivas. A necessidade de entrevista com a mãe como auxiliar na complementação de informações foi realizada, tendo em vista a necessidade de ampliar a compreensão sobre o problema. Essa estratégia tem sido apontada por outros autores como muito útil para complementar informações, já que as pessoas com autismo apresentam dificuldade de expressão verbal e dos sentimentos. (PRAÇA, 2011) A mãe revela a necessidade de inclusão social do filho no meio universitário, o que também é demonstrado pelos próprios estudantes, que se sentem desadaptados ao ambiente acadêmico. Diante das dificuldades de interação social características da pessoa com autismo, o aluno autista pode atravessar o 
curso universitário sem uma adaptação pedagógica adequada às suas necessidades bem como sem participar do ambiente social acadêmico. O trabalho em equipe é um desafio e o comportamento estranho pode gerar o distanciamento das pessoas. Assim, para além do desafio pedagógico, estamos diante do desafio da integração dessas pessoas que podem estar vivendo de forma periférica, privando o mundo das suas potencialidades e ao mesmo tempo, vivendo numa invisibilidade.

Os programas educativos devem respeitar as visões de mundo dos educandos, valorizando as suas potencialidades, evitando o que Paulo Freire chama de invasão cultural, que seria a tentativa de impor uma visão de mundo externa, freando a criatividade originária do aprendiz. (FREIRE, 2016) O ato de aprender implica em compreender a experiência do aprendiz, entrelaçando o saber acadêmico com o saber cotidiano. A aprendizagem significativa implica que o conhecimento se incorpore ao arsenal criativo do sujeito, gerando novas possibilidades de criação. (MASSINI, 2011) Todo aluno na educação superior traz as suas visões de mundo, construídas no seu contexto sociocultural, que vão ser alimentadas, modificadas e modificadoras no novo encontro com a universidade. O aluno autista, além das especificidades do seu contexto cultural, traz também idiossincrasias perceptuais que são próprias à sua condição, trazendo com isso desafios para os professores, colegas e órgãos responsáveis pela inclusão.

O sujeito aprendiz se volta para o mundo externo e exercita uma percepção crítica, escolhendo os elementos nos quais vai dirigir a sua atenção e interesse. (MASSINI, 2011) A questão que se levanta para os alunos com autismo é de como vai se dar a percepção das pessoas que tem uma integração sensorial diversa, como é o caso dos autistas? A compreensão dessas questões possibilitará a ampliação das possibilidades de inclusão da pessoa com autismo, indicando as necessidades individuais da inclusão pedagógica bem como social de cada um deles. Além disso, a identificação das potencialidades também poderá contribuir para ampliar a inclusão além de proporcionar ao aluno a possibilidade de exercer no ambiente acadêmico a sua liberdade criativa, dentro das suas potencialidades específicas e diferenciadas.

Apesar de não haver programas estruturados, fica claro que as pessoas estão sensibilizadas a reconhecer as necessidades da pessoa com autismo e abertas a tentar facilitar a inclusão. Quando 
a professora foi informada sobre o autismo do aluno que anteriormente ela havia reprovado, mudou de postura e buscou o apoio do órgão responsável pela inclusão. Na busca, a professora possivelmente tentou instrumentalizar-se para realizar uma adaptação para o aluno e para auferir os conhecimentos dele, para além dos padrões avaliativos que ela costumava utilizar. No site do órgão responsável pela inclusão de pessoas com deficiência na UFBA, não há indicação dos procedimentos para a inclusão da pessoa com autismo, não havendo menção dessa deficiência no site. As entrevistas revelaram, no entanto, que o órgão realiza reuniões com pais e professores e inclui pessoas com autismo em programas de estágio.

\section{Considerações finais}

Desse modo, apesar do apoio à pessoa com autismo ainda não estar sendo claramente divulgado pelos órgãos da universidade, fica patente uma disposição positiva para que isso seja realizado. Esse estudo exploratório e preliminar nos abre hipóteses, que deverão ser investigadas com mais detalhes. Primeiro, o autismo é uma condição que vem ganhando espaço nas referências das pessoas apenas nos últimos anos, diferente das outras deficiências, que tem um histórico mais antigo no processo de inclusão escolar na educação em geral e na universidade em particular. Na UFBA, por exemplo, o curso de libras já é obrigatório para todos os alunos matriculados em cursos de licenciatura, indicando que os novos professores estarão minimamente preparados para se comunicar em libras com os seus alunos com deficiência auditiva. Assim sendo, a não instrumentalização da universidade para receber alunos com autismo, deve-se ainda à necessidade de informação e formação de profissionais capacitados para pensar o processo de inclusão do autismo, como o que já acontece com outras deficiências. A segunda hipótese é que por ser um transtorno que envolve a saúde mental, o autismo carrega o estigma da "loucura", 5 gerando incômodo para o possuidor dessa condição, que prefere permanecer invisível, diante do receio de sofrer preconceitos.

Essas hipóteses poderão ser exploradas em estudos posteriores, que busquem expandir a compreensão do problema e ajudem a ampliar as perspectivas de inclusão, assim como possa sugerir novos procedimentos de orientação e intervenção junto aos diferentes órgãos da UFBA. 


\title{
The Inclusion of the Person with Autism in the University
}

: University for people with autism spectrum disorder (ASD) is a field that has been expanding, but with few data published in Brazil about the experience of this type of inclusion in the academy. This study seeks to know the attitudes taken by Universidade Federal da Bahia (UFBA), through Pró-Reitoria de Ações Afirmativas e Assistência Estudantil (PROAE), to improve the inclusion of people with ASD, identifying the practical measures that were conceived and made feasible for these students and how they are implemented in the practice of students with autism. The severity of the disorder varies depending on the intensity of the symptom impairment, which can range from people who have more subtle deficits such as difficulty expressing feelings and understanding metaphors, to people who can not communicate verbally or through gestures. A qualitative exploratory study was conducted, with documental research and semi-structured interviews, and a documentary research was also carried out on the Support Núcleo de Apoio à Inclusão do Aluno com Necessidades Educacionais Especiais (NAPE) website, at UFBA, and semi-structured interviews were conducted with two UFBA students diagnosed with autism, a mother of one of the students and a NAPE employee. This is an exploratory study that indicates a possible invisibility of people with autism in university, although there are programs and legislation that facilitate inclusion.

Keywords: Inclusion. Autism. University.

\section{La inclusión de la persona con autismo en la educación superior}

\begin{abstract}
: La educación superior para personas con trastorno del espectro autista (TEA) es un campo en expansión, pero con pocos datos publicados en Brasil sobre la experiencia de este tipo de inclusión en la universidad. Por lo tanto, este estudio busca conocer las acciones tomadas por la Universidade Federal da Bahia (UFBA), a través de la Pró-Reitoria de Ações Afirmativas e Assistência Estudantil (PROAE), para mejorar la inclusión de personas con TEA, identificando qué medidas prácticas se consideraron y hizo posible para estos estudiantes y cómo se implementan en la práctica de los Estudiantes con autismo. La gravedad del trastorno varía según la intensidad del deterioro de los síntomas, que puede variar desde personas con déficits más sutiles, como dificultad para expresar sentimientos y comprender metáforas, hasta personas que no pueden comunicarse verbalmente o incluso mediante gestos. Por lo tanto, se realizó un estudio exploratorio cualitativo, con investigación documental y entrevistas semiestructuradas, y se realizó una investigación documental en el sitio web del Núcleo de Apoio à Inclusão do Aluno com Necessidades Educacionais Especiais (NAPE) de la UFBA. Finalmente, se realizaron entrevistas semiestructuradas con dos estudiantes de la UFBA diagnosticados con autismo, una madre de uno de los estudiantes y una empleada de NAPE. Este es un estudio exploratorio, que sugiere una posible invisibilidad de las personas con autismo en la universidad, aunque existen programas y leyes que facilitan la inclusión.
\end{abstract}

Palabras clave: Inclusión, Autismo, Universidad. 


\section{Referências}

AMERICAN PSYCHIATRIC ASSOCIATION - APA. DSM-5: Manual diagnóstico e estatístico de transtornos mentais. Porto Alegre: Artmed Editora, 2014.

ARANHA, M. S. F. Paradigmas da relação da sociedade com as pessoas com deficiência. Revista do Ministério Público do Trabalho, Brasília, DF, v. 11, n. 21, p. 160-173, 2001.

BAGATELL, N. From cure to community: Transforming Notions of Autism. Ethos, Hanover, v. 38, n. 1, p. 33-55, 2010.

BRASIL. Lei $n^{\circ}$ 12,764, 28 de dezembro de 2012. Institui a Política Nacional de Proteção dos Direitos da Pessoa com Transtorno do Espectro Autista; e altera o $\S 3^{\circ}$ do art. 98 da Lei n. 8.112, de 11 de dezembro de 1990. Diário Oficial da União. Brasília, DF, 2012. Disponível em: http://www.planalto.gov.br/ccivil_03/_Ato2011-2014/2012/Lei/ L12764.htm. Acessado em: 13 outubro 2020.

BRASIL. Ministério da Educação. Diretrizes nacionais para a educação especial na educação básica. Brasília, DF: SEE: MEC: SEESP, 2001.

BRASIL. Ministério da Educação. Secretaria de Educação Fundamental. Parâmetros curriculares nacionais: arte. Brasília, DF: MEC: SEF, 1998.

FREIRE, P. Pedagogia do oprimido. 62. ed. Rio de Janeiro: Paz e Terra, 2016.

GIBBS, G. Análise de dados qualitativos: coleção pesquisa qualitativa. Porto Alegre: Artmed, 2009.

MASSINI, E. Educação e alteridade: deficiências sensoriais, surdocegueiras e deficiências múltiplas. São Paulo: Vetor, São Paulo, 2011.

MENDES, E. G.; FERREIRA, J. R.; NUNES, L. R. O. P. Integração/ inclusão: o que revelam as teses e dissertações em educação e psicologia. In: NUNES SOBRINHO, F. de P. (org.). Inclusão educacional: pesquisas e interfaces. Rio de Janeiro: Livre Expressão, 2003. p. 98-149.

PONDÉ, M. P.; MENDONÇA, M. S.; CAROSO, Carlos. Proposta metodológica para análise de dados qualitativos em dois níveis. História, Ciências, Saúde - Manguinhos. Rio de Janeiro, v. 16, n. 1, p. 129-143, jan./mar. 2009. Disponível em: http://www.redalyc.org/ articulo.oa?id=386138041008. Acesso em: 21 jun. 2019.

PRAÇA, É. T. P. de O. Uma reflexão acerca da inclusão de aluno autista no ensino regular. 2011. Dissertação (Mestrado Profissional em Educação Matemática) - Instituto de Ciências Exatas, Universidade Federal de Juiz de Fora, Juiz de Fora, 2011.

RODRIGUES, I. de B.; ANGELUCCI, C. B. Estado da arte da produção sobre escolarização de crianças diagnosticadas com TEA. Psicologia Escolar e Educacional, v. 22, n. 3, p. 545-555, set./ dez. 2018. 
SOLOMON, O.; BAGATELL, N. Introduction: autism: rethinking the possibilities. Ethos, v. 38, n. 1, p. 1-7, 2010.

UNIVERSIDADE FEDERAL DA BAHIA. Gabinete do Reitor. Portaria, n. 074, de 26 de março de 2008. Dispõe sobre a criação do Núcleo de Apoio à Pessoa com Necessidade Especial - NAPE/UFBA, vinculado à Pró-Reitoria de Ensino de Graduação - PROGRAD. Boletim de Pessoal. Salvador, 26 de março de 2008. Naomar Monteiro de Almeida Filho Reitor.

Submetido em 03/10/2019. Aceito em 15/10/2019. 